\title{
A CONCEPTUAL STUDY ON THE BARRIERS TO ADAPTION OF GREEN BUILDINGS IN INDIA
}

\author{
*Kranti Chintakunta
}

\begin{abstract}
:
Purpose of the study: The purpose of the study is to explore the interplay of barriers of green buildings and their effect on adoption intention of green buildings in India.

Design/Methodology: This is a conceptual paper written through review of literature in this area and expertopinion.
\end{abstract}

Findings: The present barriers to adaption of green buildings in the perspective of builders who are the immediate adaptors of green buildings are listed out and a conceptual framework is proposed.

Limitations: The framework proposed in this paper needs to be empirically validated.

Key words: Green buildings, marketing green buildings, green building adoption

\section{Introduction:The Green Building Concept:}

Resource statistics across the world suggest that the built environment is the largest resource guzzler responsible for $30 \%$ of global emissions. The construction sector, accounts for $10 \%$ of global GDP, has direct and indirect impacts on the environment, produces $23 \%$ of global greenhouse gas (GHG) emissions, and buildings are responsible for between $30 \%$ and $40 \%$ of all material flows. (ODI 2013). Rapid urban expansion fueled by economic and population growth is pushing resource usage and consequent Green House Gas emissions and climate change issues.

By improving efficiency of the built environment, and realizing the over 50\% saving potential in the building sector, there exists scope for meeting the challenges of global energy crisis and climate change.

Given that urbanization in India is less advanced than in many other countries, it presents an opportunity to avoid being locked into energyand resource-intensive infrastructure. As a significant contributor to global warming due to extensive use of energy causing greenhouse gases (GHGs) emissions, there is an imperative to develop sustainable building technologies and green buildings.( Jones Lang Lasalle Meghraj, 2008).

The promotion of green buildings, which has already begun in India, offers one way to achieve this. (ODI 2013)

Designed to address energy and resource usage throughout the life cycle, the Green Building

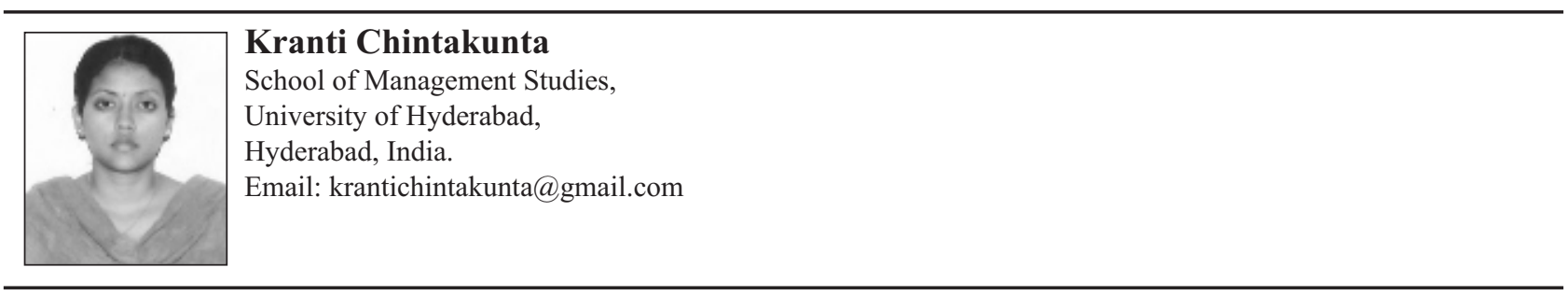


concept places less demand on natural and finite resources when compared to conventional buildings and can contribute to better environmental quality.

While many Green Building concepts and elements may exist in the market, Green Building Certification brings these scattered elements under one label. Certified Green Buildings offer the opportunity to evaluate the environmental footprint over the building's lifetime, quantify a building's resource saving capacity and finally, construct it so as to realize the potential benefits.

Certified Green Building growth rate appears rapid as evidenced by the growth in IGBC Certified buildings from one building in 2001 to more than 700 in 2016. Inspite of the phenomenal growth rate and the economic and environmental benefits they offer, Certified Green Buildings represent only about 3\% of the overall built environment in India revealing vast unexploited potential.

An examination of the Certified Green Building market reveals several barriers and challenges to the growth of this sector. These include assumptions about the economics of Green Buildings, lack of awareness of the longer term cost savings, short termism on the part of property buyers, limited access to finance for investment in the upfront costs associated with green buildings, and situations where those who pay the energy bills are not those who purchase the property (in the case of rented property). In addition, there may also be constraints on the supply side, if for example, there are

shortages of the necessary skills and knowledge in the construction sector, building materials, or energy efficient appliances (ODI 2013).

\section{The Green Building Concept}

The Green Building, also known as green construction or sustainable building, refers to a structure and using process that is environmentally responsible and resourceefficient throughout a building's life-cycle. From siting to design, construction, operation, maintenance, renovation, and demolition, Green Buildings add to economy, utility, durability, and comfort. Green buildings are designed to address the following broad concerns:

- $\quad$ Siting and structure design efficiency

- $\quad$ Energy efficiency

- Water efficiency

- Materials efficiency

- Indoor environmental quality enhancement

- Operations and maintenance optimization

- Waste reduction

Green buildings are designed to reduce the overall impact of the built environment on human health and the natural environment by,

- Efficiently using energy, water, and other resources

- Protecting occupant health and improving employee productivity

- Reducing waste, pollution and environmental degradation

\section{Several benefits accrue by using the Green building concept:}

- 30 to 40 per cent reduction in operation cost

- Resource efficiency and savings on resource expenditure

- Green corporate image

- Incorporates latest techniques and technologies and this has a positive impact on cost 


\section{Green building growth rate in India and the world}

Asian statistics depict that building growth will be concentrated in cities in Asia. The growth of Asian cities is astounding, with many doubling their population every 15 to 20 years. Currently, Asia holds more than half of the world's megacities with more than 10 million people, and that number is rapidly rising. China is now constructing almost half of the world's new floor space and built up area in India has more than doubled from 2000 to 2005.

The need for buildings is increasing hand in hand with the rising population. By 2030, 60 percent of Asians i.e. around 5 billion people are expected to occupy these buildings.

While Green buildings were driven by moral reasons earlier, in the interest of social or environmental impact, they are now influenced by market factors and seen as a business opportunity. This suggests considerable potential for the further promotion of green buildings to reduce the environmental impact of construction and urbanisation in India. (ODI 2013) There is potential to reduce GHG emissions by 142 megatons (Mt) a year by 2020 and by $296 \mathrm{Mt}$ a year by 2030 through the adoption of energy-efficient measures. The energy embodied in building materials should also be taken into account. (ODI 2013)

The potential notwithstanding, there also exist significant barriers to the proliferation of Green Buildings in India.

\section{Conceptual framework}

Barriers for Green Building growth in India

The following are barriers identified and most discussed in the literature.

\section{Perception barriers}

The first and foremost constraint for the proliferation of green buildings is the lack of information and incorrect perception. It is generally believed that green buildings cost more and have long gestation periods. Although experts highlight the advantages of green buildings, this information does not reach developers and customers. (Jones Lang Lasalle Meghraj 2008).

The perception of high cost is true not just in the case of India but also across the countries where Green Buildings are in vogue. As per the World Green Building Trends survey, the responding construction sector firms perceive the higher initial cost of green buildings as the principal barrier to investment.

The Turner report also reveals the same trend in the survey it conducted in the United States. "The perception that Green buildings have higher costs and a lengthy payback period remains a significant obstacle. Although most executives said it was extremely or very likely they would invest in Green features such as improved energy efficiency (82\%) and improved water efficiency (71\%) if undertaking a construction project, many are concerned about the costs of Green buildings and the length of the payback period. The issues most often considered to be extremely or very significant obstacles to Green construction were higher construction costs (66\%), higher operating and maintenance costs (56\%), and payback too long (56\%).”

Though these statistics exist, the perception that Green Buildings are expensive perhaps has its roots in the public's primary concern about financial costs than sustainability aspects or long term savings. Given the perception of higher costs, Green Buildings are subsequently perceived as a luxury market thus discluding the affordable housing sector. (ODI 2013)

Apart from the high cost perception, one of the main barriers encountered in encouraging green 
building practices is lack of awareness of the benefits amongst the users of building. (ODI 2013).

The perception of high costs and shortfall in knowledge appear joined in customers' minds.

\section{Communication barriers}

Though the rating systems in vogue indicate potential savings of adopting Green Building practices, the results do not appear to be comprehensively documented post occupancy.

Also, there is no systematic means to find out whether certified buildings are meeting their intended standards. (ODI 2013).

The shortfall in evidence and lack of validation tools portray an ambiguous image of Green Building performance.

The variety of rating systems, and potential competition between them, may also confuse consumers. (ODI 2013) In an attempt to gainsay competing rating systems, the rating systems may themselves contribute to the existing confusion while they should ideally be dispelling myths about Green Buildings.

\section{Cost barriers:}

The cost barriers involved in the adaption of green buildings involves various costs. First one is Time cost. The cost involved here is the time taken to realize Green Building through the Integrated Design Process. Integrated Design is an integral part of the Green Building Construction process. It is a highly collaborative process which involves the entire project and brings all the systems involved in the construction process onto one platform.

Integrated Design Process however is perceived as a significant barrier to Green Building growth due to the time involved in the process.

As per the Turner Report, the Integrated Design process can take additional time to arrive at the optimal design solution for the building being constructed. But since time is a critical element and delays may translate into cost, the time spent on Integrated Design proves to be a barrier.

The second cost discussed in the literature as a barrier to adaption of green buildings is the cost of securing Rating as Green. A building may still adopt Green practices but it may lose out on the full spectrum of features which can be secured by choosing a Rating process. Rating adds cost to the Green Building process as specialised and accredited professionals and practices are involved. Not all building stakeholders possess the financial wherewithal to fund the surplus cost owing to Rating. Variable Certification exists under each Rating system but this too appears beyond the ambit of the middle, lower mid and low income groups. With this being the case, full-fledged conversion to Green construction may not be accomplished unless the Rating system introduces measures to include the thus far excluded building types.

\section{Policy barriers}

Two out of the twelve focus areas of the 12th FYP (2012-2017) are supportive of green construction. While Area 10 and 11 focus on 'Lighting, Labelling and Super-Efficient Equipment Programme', Area 11 is regarding 'Faster Adoption of Green Building Codes'. (ODI 2013)

Policy making however is affected by differences in adoption between Central and State levels, absence of a nationally accepted standard for Green Construction and presence of competing Rating standards. Though these policy initiatives have taken place, rating itself continues to be a voluntary action, and not a compulsion. Inspite of a policy's best intentions, voluntary adoption and implementation of Green Building codes cannot be construed as 
watertight. Possibilities of green washing and obscure disclosure of building performance exist which will only further damaging perceptions of Green Buildings, which in turn will affect their proliferation.

Increased Green Building activity then seems to need the support of a rigorous policy environment to become a mainstream practice which is yet to be.

\section{Financing barriers}

One of the oft discussed issue with regard to Green Buildings is the Building investors interest in short term gains and not the overall savings which could be realized over the lifetime of the building. The savings realized at the end of the yearly accounting period do not appeal highly to Financial institutions. The high upfront costs of Green buildings also speak against investment unless the Financial Institution advancing monetary support can see beyond the accounting period.

\section{Market factors}

It has been observed that market factors carry eminence over the interest in doing well in case of Green Buildings. (ODI 2013). Green Buildings are being increasingly Seen as a business opportunity, perceived as profitable differentiating factors and may not garner acceptance if they end up being dismissed as a fad.

In times of economic ambiguity, cost cutting is the first line of fire to be adopted. The same seems to apply to Green Buildings also. "Any turbulence in the real estate industry will directly affect developers' propensity to invest in additional cost centres such as a premium on green buildings." (Jones Lang Lasalle Meghraj 2008)

Green Building practices mandate that the construction material must be sourced locally, within a specified radius. The reasoning is that materials sourced locally have less environmental impact when integrated into the building, are more suitable for the locality and emissions generated during transportation can be avoided. While these are noble intentions, there are difficulties in finding

local suppliers who have a certification for having responsibly sourced these materials. That the local market is not always regulated also adds to the problem. Going further, the lack of available materials might also discourage developers to pursue green building developments. (Jones Lang Lasalle Meghraj 2008). Thus material availability is considered as one among the market factors affecting the adaption of green buildings. The Green Building material and equipment market appears to be gradually emerging from nascence. The market however also consists of ambiguous labels, green washing, lack of clarity about the credibility of the material or suppliers, irregularity and scattered knowledge about the suppliers.

While directories are maintained by the rating outfits, these are straightforward lists which do not reveal much about the types and size of companies involved in Green Material business. (ODI 2013). Improved information would help to reduce transaction costs, improving efficiency and competition, which would help the industry in general (Kalra, R. and Bonner, R 2012). Understanding the nature of players in the Green material market and their needs, is key to creating and furthering a commercial market for green buildings. (ODI 2013). While IGBC has an accreditation programme and so does GRIHA through which Green Building professionals are accredited, there continues to be a lacuna in qualified professionals in consulting, facilitating, planning, designing and constructing Green buildings. The sector is 
marked by skill deficit also given that only $6 \%$ of the construction sector have necessary skills to engage in Green Buildings. Shortage of contractors and gaps in technical training also contribute to the problem. (ODI 2013)

IGBC data suggests that the demand for Green Buildings surpasses the capacity of the existing pool of Green Building professionals. If technical capacities are not strengthened through reforms in engineering and related education, it will prove hard to meet the needs of even existing Green Buildings.

\section{Conceptual framework}

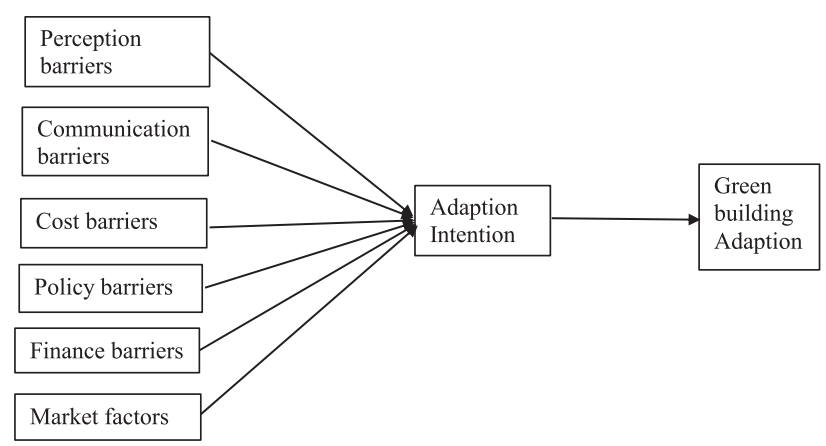

The conceptual framework proposes that the stated factors - perception barriers, communication barriers, cost barriers, policy barriers, finance barriers and market factors affect the adaption intention of green buildings among the builders. The green building adoption depends on the adaption intention.

\section{Conclusion}

The theory of Diffusion of Innovation suggests a period of 15 to 25 years before a new technology moves from the Early Adopter stage to being adopted by $90 \%$ of the market. (Rogers, E 2003)

Elaborating on this theory, the major issues in determining the rate of adoption of innovation include Relative economic or social advantage, Compatibility with existing methods, Ease of trial at relatively low cost, Observability and
Simplicity of use. (Yudelson 2008) While economic advantage, though debated but generally considered a positive factor and compatibility with existing methods are considered favorable to Green Buildings, the remaining three factors are yet to be realized in case of Green Buildings.

Further research in this area will validate the constructs defined and the proposed relationship among factors.

Despite the discussion about innovation adoption, the most compelling factor in favor of Green Buildings is rapidly diminishing resource base of the country with most metros being power stressed and water stressed. Increasing incidence of natural calamities is placing more pressure on these stressed conditions and accentuated by the needs of growing population. If not in business interest, the construction Industry is bound to adopt Green Building practices owing to resource paucity.

Irrespective of whether these green practices are through an established Rating system, building owners would possibly adopt complete to partial Greening depending on their capacity. Green construction consulting firms are sprouting across the country showing a rising interest in building Green.

The US market appears to be shifting in a big way towards green building as evidenced by Turner Constructions report. There appears to be a resonance in India also. While reports suggest that perceptions of Green Buildings as expensive are prolific, the number of takers especially in case of Rated Certified Green Buildings is growing.

Green Building consultants opine that the incremental cost is gradually on the decline and the difference in cost is likely to be erased soon. The reasons they attribute include gradually increasing availability of Green materials and 
also increasing awareness. Though moving at a slow pace, in commercial spaces especially, Green Building activity appears on the rise and it can have a snowballing effect on the rest of the nation's landscape.

Research also predicts that increasing awareness will further interest in Green Buildings and augment competency in real estate professionals. Availability of information and local materials will eventually improve. "However, the prospect of a recession in the real estate sector and the need to modify the green building criteria to suit local standards can still cast a shadow of uncertainty over the development of green buildings." (Jones Lang Lasalle Meghraj 2008)

With government policy and reform leading the way and with large-scale awareness and capacity-building programmes, Greening the construction sector and accomplishing sustainability goals of the nation should not be a faraway possibility.

\section{References}

- Carn, N., Rabianski, J., Racster, R., and Seldin, M. Real Estate Market Analysis: Techniques and Applications, Englewood Cliffs, NJ: Prentice Hall, 1988.

- Devi T, Laxmi, Green Building - Market opportunities and challenges, 2012.

- Global Green Building Trends Smart Market Report, McGraw Hill Construction, 2008.

- Green building: Case Study, Organisational Development Institute, 2013. fi IPCC. (2007). Contribution of Working Groups I, II and III to the Fourth Assessment Report of the Intergovernmental Panel on Climate Change. Geneva, Switzerland: IPCC.

- Jones Lang Lasalle Meghraj (2008) Greenomics: Cost Efficiency of Green Buildings in India
- Kalra, R. and Bonner, R. (2012) 'Addressing Climate Change with LowCost Green Housing'. Washington, DC: World Bank.

- Khosla, Radhika "Constructing Change: Energy Efficiency and India's Buildings Sector, The Hindu Business Line, January 2012.

- Krishnan Gowri, Green Building Rating Systems - An Overview ASHRAE journal November 2004.

- LEED reference package version 2.0, US, Green Building Council, June 2001.

- Parikh, K. (2011) 'Interim Report of the Expert Group on Low Carbon Strategies for Inclusive Growth'. New Delhi: Planning Commission, Government of India.

- Ramesh S and Khan, E. (2013). Energy Efficiency in Green Buildings - Indian Concept. International Journal of Emerging Technology and Advanced Engineering Volume 3, Special Issue 3: ICERTSD 2013, Feb 2013, pages 329-336.

- Rogers, E. (2003) Diffusion of Innovations, 5 th edn. New York: Free Press.

- Turner Construction Company. Survey is available at:

http://www.turnerconstruction.com/greenbuilding (accessed February 6, 2016).

- UN Habitat (2011) 'Sustainable Building Practices for Low Cost Housing: Implications for Climate Change Mitigation and Adaptation in Developing Countries'. Shelter Initiative for Climate Change Mitigation and Adaption (SICCMA).

- World Green Building Trends Smart Market Report, McGraw Hill Construction, 2013, 
- Yudelson, J. (2008). Marketing Green Building Services: Strategies For Success. Burlington, MA: Elsevier Ltd.

\section{Online articles}

- http://www.worldgbc.org/files/8613/6295 /6420/World_Green_Building_Trends_Sm artMarket_Report_2013.pdf

- Iyer, B.J. (2011) 'India's green building market to worth $\$ 30$ bn', Sulekha.com B2B. Available at:

http://smehorizon.sulekha.com/india-sgreen-building-market-to-worth-30bn_constructionviewsitem_5072 (accessed 15 October 2013).
- Building Energy Efficiency: Why Green Buildings are Key to Asia's Future, Asia Business Council Report, (2008). Available at:

http://www.asiabusinesscouncil.org/docs/ BEE/BEEBook.pdf

- http://www.legacy2030.com/2011/05/ green-building-leed.html 